\title{
ANALISIS PERFORMA KOMPOR GASIFIKASI BIOMASSA TIPE FORCED DRAFT MENGGUNAKAN VARIASI JUMLAH BAHAN BAKAR TONGKOL JAGUNG
}

\author{
Romi Djafar ${ }^{1)}$, Yunita Djamalu( ${ }^{1}$, Siradjuddin Haluti ${ }^{1)}$, Sjahril Botutihe ${ }^{1)}$ \\ ${ }^{1}$ Tim Pengajar Pada Program Studi Mesin dan Peralatan Pertanian, Politeknik Gorontalo \\ Email : romidjafar@poligon.ac.id
}

\begin{abstract}
ABSTRAK
Ketersediaan energi semakin sedikit mendorong peningkatan harga bahan bakar minyak yang pada akhirnya menyusahkan masyarakat terutama kelompok ekonomi lemah. Guna mengatasi masalah harga minyak dan gas yang semakin mahal dan cadangannya yang terbatas maka diperlukan usaha yang terprogram dan terarah untuk mencari energi alternatif. Salah satu upaya yaitu penggunaan biomassa digunakan pada sektor rumah tangga misalnya untuk keperluan memasak. Namun masyarakat umumnya menggunakan biomassa dengan cara dibakar secara langsung. Sehingga metode pembakaran yang dihasilkan kurang efesien dan tidak ramah lingkungan. Maka dari itu, sejak dahulu kompor gasifikasi biomassa telah dibuat dan tingkat pengembangannya sampai dengan sekarang ini. Berbagai desain dan model telah banyak dikembangkan untuk mengkonversi biomassa sebagai sumber energi alternatif untuk menghasilkan kinerja yang lebih baik. Namun rancangan kompor gasifikasi yang sudah ada tersebut masih memiliki berbagai kendala antara lain proses gasifikasi yang belum optimal dan kualitas pembakaran yang rendah. Tujuan penelitian ini adalah fabrikasi kompor gasifikasi biomassa tipe forced draft menggunakan blower sebagai udara primer untuk skala laboratorium. Gasifikasi biomassa menarik untuk dikembangkan mengingat Propinsi Gorontalo telah menetapkan pertanian sebagai program unggulan yang berbasis jagung. Saat ini limbah hasil pertanian berupa tongkol jagung yang melimpah tersebut tidak dimanfaatkan dan hanya dibakar secara langsung oleh masyarakat. Terutama masyarakat yang tinggal dipemukiman pelosok desa bahkan daerah terisolir sehingga dipastikan bahwa jangkauan suplai energi listik dari PLN tidak terdapat pada daerah tersebut. Oleh karena itu, Teknologi kompor gasifikasi yang dapat mengkonversi biomassa menjadi energi panas yang hemat energi dan ramah lingkungan sebagai solusi yang tepat untuk diperkenalkan kepada pemerintah daerah maupun komunitas masyarakat yang ada. Tujuan Penelitian ini adalah rancang bangun dan fabrikasi kompor biomassa dengan bahan baku tongkol jagung. Hasil fabrikasi telah diuji kinerjanya dengan variasi ukuran jumlah bahan bakar yaitu 1; 2 dan $3 \mathrm{~kg}$ masing-masing dengan ukuran bahan bakar $1 \mathrm{~cm}$. Metode yang digunakan adalah water boiling test (WBT) terhadap 3 liter air. Berdasarkan pengujian didapatkan hasil berupa start-up tercepat terjadi pada menit ke 4 dan waktu terlama pada menit ke 8, komsumsi bahan bakar yang dihasilkan berturut-turut $2.65 \mathrm{~kg} / \mathrm{h} ; 1.92 \mathrm{~kg} / \mathrm{h} \mathrm{dan} 2.6 \mathrm{~kg} / \mathrm{h}$. Power input berturut-turut $8.2 \mathrm{kWh} ; 5.9 \mathrm{kwh}$ dan $9.3 \mathrm{kwh}$. Power output yang didapatkan adalah terendah sebesar $1.36 \mathrm{kWh}$ dan tertinggi sebesar $2.1 \mathrm{kWh}$. Total operating time dari kompor masing-masing sebesar 56; 78 dan 85 menit. Sedangkan efesiensi termal kompor gasifikasi dihasilkan sebesar 23.6\%.
\end{abstract}

Kata Kunci: Kompor, Biomassa, Hemat Energi, Bahan Bakar

\subsection{Latar Belakang}

Ketersediaan sumber energi fosil semakin sedikit mendorong kenaikan harga bahan bakar minyak yang pada akhirnya menambah beban masyarakat terutama kelompok ekonomi lemah. Guna mengatasi masalah harga minyak dan gas yang semakin mahal serta cadangannya yang terbatas maka diperlukan usaha yang terprogram dan terarah untuk mencari energi alternatif yang berasal dari biomassa.

Biomassa merupakan bahan organik yang dihasilkan melalui fotosintesis baik berupa produk atau sisa produk. Contohnya tanaman, pepohonan, limbah pertanian, kotoran ternak . Selain digunakan untuk bahan primer serat, bahan pangan, pakan ternak minyak nabati dan bahan bangunan dan sebagainya. Energi biomassa dapat menjadi energi alternafif pengganti bahan bakar fosil karena beberapa sifatnya yang menguntungkan yaitu dapat dimanfaatkan secara lestari karena sifatnya yang dapat diperbaharui, relatif tidak mengandung unsur sulfur, karbon monoksida sehingga tidak berbahaya bagi kesehatan.

Biomassa yang digunakan umumnya sebagai bahan bakar primer menggunakan tungku-tungku tradisional untuk keperluan memasak pada sektor rumah tangga. Penggunaan tungku tradisional menghasilkan pembakaran yang kurang sempurna dan tingkat efisiensi yang rendah. Sehingga menambah polusi lingkungan akibat asap yang berlebihan yang pada akhirnya menimbulkan efek samping yang berbahaya bagi 
kesehatan. Namun, disamping tungku sederhana sejak dahulu telah dikembangkan alat untuk keperluan memasak bagi masyarakat urban berupa kompor gasifikasi biomassa yang dinilai lebih efisien dan efektif bagi masyarakat serta ramah lingkungan.

Berbagai penelitian dan pengembangan yang telah dilakukan untuk mendesain dan evaluasi kinerja dari kompor gasifikasi biomassa dengan mengatur parameter untuk mendapatkan performa kompor yang lebih baik. Kompor gasifikasi H. S. Mukunda dkk, (2010). Pengembangan kompor dengan blower tunggal yang memiliki kadar emisi rendah, kemapuan stabil, yang dapat dikontrol menggunakan bahan bakar dalam bentuk pellet dengan basis suplai udara menggunakan fan sebagai udara primer pembakaran beserta secondary air untuk pembakaran stoikiometri. Metode pengembangan eksperimen dilakukan menggunakan berbagai tipe bahan bakar, ukuran ruang bakar dan desain ruang suplai udara pembakaran. Hasil penelitian menunjukkan bahwa desain yang memiliki efisiensi tinggi serta kadar emisi rendah sangat dipengaruhi oleh perbandingan udara dan bahan bakar yang benar.

Performance evaluation of three types of forceddraft cook stoves using fuel wood and coconut shell, P. Raman dkk, 2013 Tujuan penelitian adalah evaluasi tiga tipe kompor gasifikasi menggunakan dua jenis bahan bakar. Metode yang digunakan adalah water boiling test (WBT). Hasil penelitian disimpulkan bahwa efesiensi termal dan specific fuel consumption Philips cook hampir tidak bergantung pada jenis bahan bakar. Sedangkan TERI's stove lebih meningkat efesiensi dan laju komsumsi bahan bakarnya.

Pengaruh pemilihan parameter terhadap performa dan isi dari pembakaran biomassa pada kompor gasifikasi. (S.C. Bhattacharya dkk, 2002). Tujuan penelitian menentukan jenis kompor yang memiliki efisiensi yang lebih tinggi berdasarkan jenis bahan bakar dan memiliki kadar emisi rendah yang dibandingkan dengan tungku tradisional. Metode adalah water boiling method (WBT). Hasil eksperimen menunjukkan bahwa dihasilkan performa kompor yang memiliki tingkat emisi yang rendah sesuai rekomendasi PCIA. Berdasarkan percobaan yang dilakukan direkomendasikan untuk mendesain kompor yang sudah ada atau membuat desain yang baru, sehingga diperoleh hasil desain yang lebih lebih baik dengan tingkat efesiensi yang lebih tinggi.

Penelitian selanjutnya adalah fabrikasi dan evaluasi performa kompor biomassa,
(Amiebenomo, S.O dkk, 2013). Kajian yang dilakukan yaitu pengembangan kompor biomassa yang sesuai dengan mengatur bagian ruang bakar berupa isolasi ruangan pembakaran untuk mengurangi kerugian panas yang terjadi pada dinding ruang bakar. Kesimpulan dari penelitian adalah kinerja kompor biomassa yang dikembangkan memiliki performa yang efisien dan rendah terhadap polusi udara.

Berdasarkan beberapa literatur sebelumnya maka penelitian ini bertujuan re-desian kompor biomassa tipe forced draft dengan udara primer berasal dari fan yang dihubungkan dengan arus listrik sebagai udara pembakaran menggunakan bahan baku tongkol jagung. Modifikasi yang dilakukan pada penelitian adalah jarak (Gap) antara dinding luar dan ruang bakar. Beberapa faktor yang mempengaruhi kinerja kompor gasifikasi yaitu sistem pasokan udara dan jenis biomassa. Sistem pasokan udara kompor gasifikasi dibedakan menjadi dua tipe yaitu pasokan udara secara alami (natural draft) dan pasokan udara menggunakan bantuan kipas angin (forced draft).

\subsection{Pengertian Kompor Gasifikasi}

Kompor gasifikasi adalah salah satu teknologi pemanfaatan biomassa untuk keperluan memasak pada sektor rumah tangga. Gasifikasi biomassa merupakan suatu proses dekomposisi termal dari bahan-bahan organik melalui pemberian sejumlah panas dengan suplai oksigen terbatas untuk menghasilkan synthesis gases yang terdiri dari $\mathrm{CO}, \mathrm{H} 2, \mathrm{CH} 4$ (selanjutnya disebut dengan syn-gas) sebagai produk utama dan sejumlah kecil arang karbon dan abu sebagai produk ikutan. Gasifikasi pada dasarnya adalah alat yang memungkinkan mengubah bahan bakar padat menjadi bahan bakar gas oleh proses termokimia akibat oksidasi cepat. Proses ini melibatkan oksidasi partial dan temperatur tinggi, reaksi oksidasi dan reduksi diantara bahan bakar padat-udara.

Desain kompor gasifikasi biomassa erat kaitannya aplikasi perpindahan kalor, pembakaran dan prinsip aliran fluida untuk mendapatkan pembakaran yang stoikiometri dengan kebutuhan excess air yang minimal. Perpindahan kalor akan maksimal dari api ke tungku masak dan kalor yang hilang minimum dapat terjadi, dengan cara menambahkan beberapa parameter pengeporasian dan penambahan subsistem yang dimiliki sebuah kompor tersebut.

\subsection{Analisis Parameter Input Dan Output Kompor Gasifikasi \\ Desain dan fabrikasi kompor biomassa akan} maksimal dengan mempertimbangkan parameter penting. Dalam menentukan ukuran bahan bakar sesuai dengan kompor dengan memperkirakan output daya yang diharapkan. Dengan demikian ukuran sebuah kompor 
dapat ditentukan dengan menggunakan beberapa parameter penting sebagai berikut.

a. Energi input adalah jumlah energi yang butuhkan yaitu mengacu pada jumlah panas yang dipasok oleh kompor. Hal ini dapat ditentukan dengan mengetahui jumlah makanan atau air yang direbus dengan persamaan:

$$
Q n=\frac{M f x E s}{T}
$$

dengan:

Qn = Energi yang dibutuhakan $(\mathrm{kCal} / \mathrm{hr})$

Mf = Massa makanan $(\mathrm{kg})$

Es $\quad=$ Energi spesifik, $\mathrm{kCal} / \mathrm{kg}$

$\mathrm{T}=$ Cooking time (hr)

b. Sensible Heat adalah energi panas yang dibutuhkan untuk menaikkan suhu air yang diukur sebelum air mendidih dan sesudah mendidih.

$\mathrm{SH}=\mathrm{Mw} \times \mathrm{Cp} \times(\mathrm{Tf}-\mathrm{Ti})$

SH : Sensible heat (Kcal)

$\mathrm{Mw}$ : Mass of water, $\mathrm{kg}(1 \mathrm{~kg} / \mathrm{liter})$

$\mathrm{Cp}$ : Spesific heat of water, $1 \mathrm{Kcal} / \mathrm{kg}-{ }^{\circ} \mathrm{C}$

Tf : Temperature of water at boiling $\left({ }^{\circ} \mathrm{C}\right)$

$\mathrm{Ti}$ : Temperature of water before boiling $\left({ }^{\circ} \mathrm{C}\right)$

c. Latent Heat adalah jumlah energi yang digunakan untuk menguapkan air dengan menggunakan formula sebagai berikut.

$\mathrm{LH}=\mathrm{We} \times \mathrm{Hfg}$

LH $=$ Latent Heat (Kcal)

$\mathrm{We}=$ Weight of water evaporated $(\mathrm{kg})$

d. Heat Energi Input yaitu jumlah energi yang diperlukan dalam hal ini jumlah energi bahan bakar yang diumpankan kedalam kompor dapat ditentukan dengan persamaaan sebagai berikut.

$$
\mathrm{QF}=\mathrm{WFU} \times \mathrm{HVF}
$$

QF = Energi panas yang tersedia pada bahan bakar (Kcal)

$\mathrm{WFU}=$ Berat bahan bakar yang digunakan $(\mathrm{kg})$

$\mathrm{HVF}=$ Heating value of fuel $(\mathrm{Kcal} / \mathrm{kg})$

f. Laju komsumsi bahan bakar spesifik

$$
F C R=\frac{Q n}{H V f \cdot \eta g}
$$

dengan:

$\mathrm{FCR}=$ Fuel consumption rate $(\mathrm{kg} / \mathrm{hr})$

Qn = Heat energy needed $\mathrm{Kcal} / \mathrm{hr}$

$\mathrm{HVf}=$ Heating value of fuel $(\mathrm{Kcal} / \mathrm{kg})$

$\mathrm{Hg}=$ Efesiensi kompor $(\%)$

e. Perhitungan efisiensi termal

Efesiensi termal adalah perbandingan antara nilai kalor yang diterima oleh air dengan nilai kalor yang terkandung dalam bahan bakar. Perhitungan efisiensi termal dilakukan dengan menggunakan persamaan umum yang biasa digunakan metode water boiling test (WBT) sebagai berikut.

$$
\eta=\frac{S H+L H}{H F x W F} \times 100
$$

dengan:

$$
\begin{array}{ll}
\eta & =\text { Efficiencies thermal }(\%) \\
\text { Sh } & =\text { Sensible heat }(\text { Kcal }) \\
L H & =\text { Latent Heat }(\text { Kcal }) \\
H F & =\text { Heating value of fuel }(\text { Kcal } / \mathrm{kg}) \\
W F & =\text { Weigh of fuel used }(\mathrm{kg})
\end{array}
$$

g. Power Input adalah jumlah energi yang dipasok kedalam kompor berdasarkan bahan bakar yang digunakan.

$$
\mathrm{Pi}=0.0012 \times \mathrm{FCR} \times \mathrm{HVF}
$$

$$
\begin{aligned}
& P i=\text { Power input }(\mathrm{kW}) \\
& F C R=\text { Fuel consumption rate } \mathrm{kg} / \mathrm{hr} \\
& H V F=\text { Heating value of fuel, Kcal/kf }
\end{aligned}
$$

h. Power output adalah jumlah energi yang dihasilkan oleh kompor untuk memasak.

$$
\text { Po }=\text { FCR } \times \text { HVF } \times \eta
$$

$$
\begin{aligned}
& P o=\text { Power output }, \mathrm{kW} \\
& F C R=\text { Fuel consumption rate } \mathrm{kg} / \mathrm{hr} \\
& H V F=\text { Heating value of fuel, Kcal/kf } \\
& \eta=\text { Thermal Effeciencies }(\%)
\end{aligned}
$$




\section{METODELOGI PENELITIAN}

Metodelogi penelitian digunakan untuk mengetahui gambaran umum tentang proses penelitian yang akan dilakukan. Gambar 1 merupakan gambaran umum sistematika penelitian yang dilakukan sebagai berikut.

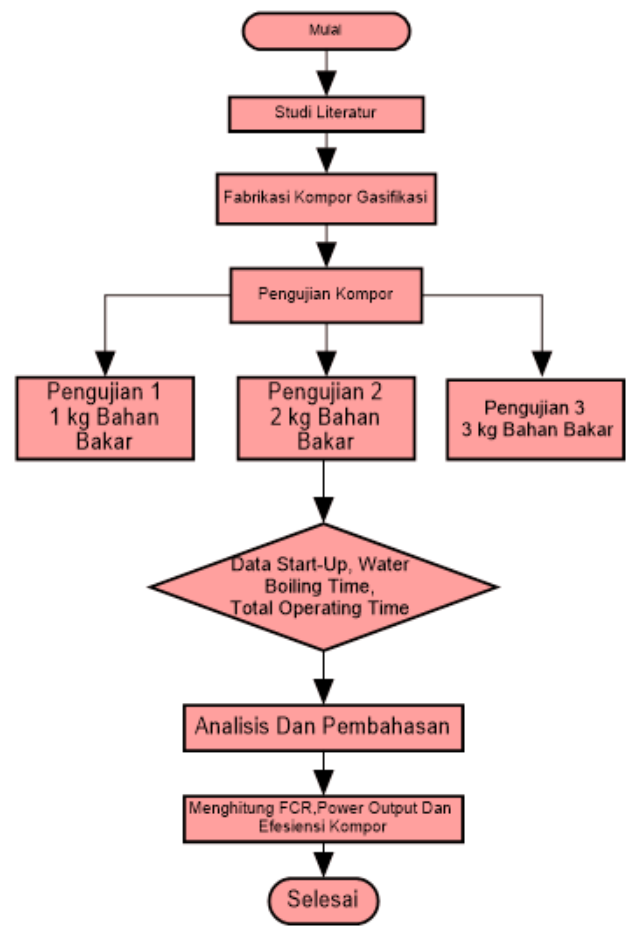

Gambar 1. Diagram alir penelitian

Berdasarkan diagram alir dapat diketahui bahwa penelitian diawali dengan proses desain kemudian dilanjutkan dengan fabrikasi kompor gasifikasi. Hasil fabrikasi tersebut akan dilakukan pengujian sebanyak tiga tahapan dengan memvariasikan ukuran bahan bakar yaitu 1;2 dan $3 \mathrm{~kg}$ bahan bakar tongkol jagung yang telah di potong-potong sebesar $1 \mathrm{~cm}$. Pada proses pengeporasian yaitu start-up menggunakan selembar kertas yang telah dicelupkan dalam cairan solar yang berguna sebagai pemicu penyalaan awal. Ketika start-up dimulai maka disaat yang sama fan langsung dihubungan dengan arus listrik sehingga udara luar akan terdorong kedalam sebagai udara untuk membantu proses pembakaran. Dalam hal ini posisi kecepatan fan diatur pada posisi konstan yaitu 12 volt dan 0.2 A. Selanjutnya akan dievaluasi kinerja kompor tersebut terutama menghitung laju komsumsi bahan bakar yang digunakan, power output yang dihasilkan, dan efesiensi dari kompor tersebut. Bagian-utama dari kompor gasifikasi pada penelitian dapat ditunjukkan pada Gambar 2 sebagai berikut.

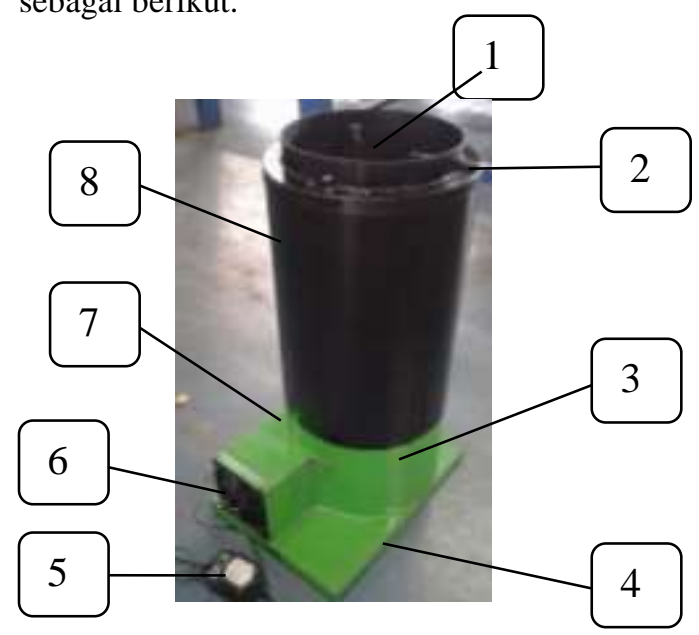

Gambar 2. Bagian-bagian utama kompor Gasifikasi

\begin{tabular}{|ll|l|}
\hline 1. & Ruang Pembakaran & 5. Adaptor \\
\hline 2. & Support & 6. Rotari fan \\
\hline 3. & Ash Box & 7. Lubang Udara secondary \\
\hline 4. & Landasan & 8. Bodi Luar \\
\hline
\end{tabular}

Bagian-bagian utama dari kompor gasifikasi memiliki ukuran yaitu bodi luar berdiameter 12 inci, ruang bakar memiliki $\varnothing 20$ inchi, tinggi total $58 \mathrm{~cm}$, ukuran box udara primer $20 \times 20 \mathrm{~cm}$, Box ash $\emptyset=12$ inch, $\mathrm{d}=6$ " $\mathrm{x} 21 \mathrm{~cm}$ dan Gap antara dinding luar dan ruang bakar sebesar $2.5 \mathrm{~cm}$.

\subsection{Prosedur Penelitian}

Beberapa tahapan yang dilakukan dalam penelitian sebagai berikut.

1. Menyiapkan bejana/panci yang sudah berisi air sebanyak $3 \mathrm{~kg}$.

2. Mengisi bahan bakar berupa tongkol jagung yang sudah berukuran $1 \mathrm{~cm}$ sesuai dengan jumlah bahan bakar yang divariasikan. ( $1 \mathrm{~kg} ; 2 \mathrm{~kg}$ dan $3 \mathrm{~kg}$ )

3. Siapkan selembar kertas untuk dinyalakan sebagai pemicu awal dalam start-up.

4. Siapkan stopwatch untuk menghitung total waktu operasi.

5. Apabila semua peralatan untuk mendukung proses penelitian sudah tersedia maka langkah selanjunya menyalakan kompor.

6. Mengamati proses start-up apakah sudah sempurna.

7. Ketika nyala api sudah terbentuk maka dilakukan pendidihan air dan amati lama waktu proses pendidihan air dengan stopwatch.

8. Pengujian dilakukan sebanyak tiga kali dengan jumlah bakar bakar yang berbeda. 


\subsection{Hasil Dan Pembahasan}

Eksperimen pengujian dan evaluasi performa kompor gasifikasi tipe forced draft meliputi data waktu start-up, laju komsumsi bahan bakar (fuel consumption rate), analisis power input, latent heat, sensible heat, efesiensi termal dan power output. Data yang ditunjukkan pada Tabel 1 merupakan variasi yang akan dilakukan dalam peneltian sebagai berikut.

Tabel 1. Jumlah Variasi Ukuran Bahan Bakar

\begin{tabular}{|c|c|c|c|}
\hline $\begin{array}{c}\text { Jumlah } \\
\text { bahan } \\
\text { bakar }(\mathrm{Kg})\end{array}$ & $\begin{array}{c}\text { Ukuran } \\
\text { bahan } \\
\text { bakar }(\mathrm{cm})\end{array}$ & $\begin{array}{c}\text { Jumlah air yang } \\
\text { digunakan } \\
(\mathrm{kg})\end{array}$ & $\begin{array}{c}\text { Kadar } \\
\text { air BB } \\
(\%)\end{array}$ \\
\hline 1 & 1 & 3 & 19 \\
\hline 2 & 1 & 3 & 19 \\
\hline 3 & 1 & 3 & 19 \\
\hline
\end{tabular}

Tabel 1. menunjukkan parameter input yang digunakan dalam penelitian. Setiap pengujian menggunakan bahan bakar yang berbeda dengan jumlah pendidihan air masing-masing sebanyak 3 $\mathrm{kg}$ dengan tingkat kadar air tongkol jagung sebesar 19\%. Data hasil pengujian dapat ditunjukkan dalam Tabel 2 sebagai berikut.

Tabel 2. Data Hasil Pengujian

\begin{tabular}{|c|c|c|c|c|c|c|c|c|c|}
\hline 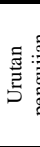 & 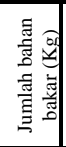 & 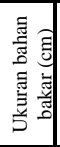 & 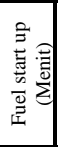 & 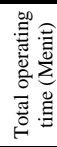 & 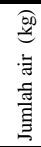 & 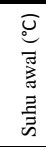 & 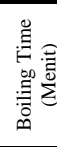 & 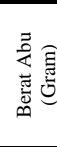 & 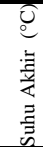 \\
\hline 1 & 3 & 1 & 4 & 86 & 3 & 29 & 12 & 38.3 & 100 \\
\hline 2 & 2 & 1 & 5 & 78 & 3 & 29 & 16 & 25.8 & 100 \\
\hline 3 & 1 & 1 & 8 & 56 & 3 & 29 & 18 & 13.1 & 100 \\
\hline & 5.6 & 80.3 & 3 & 29 & 15.3 & 25.7 & 100 \\
\hline
\end{tabular}

Tabel 2 menunjukkan data hasil pengujian menggunakan metode water boiling tes (WBT). Percobaan dilakukan sebanyak tiga kali dengan jumlah bahan bakar yang berbeda. Berdasarkan data pengujian didapatkan hasil pengujian dengan $3 \mathrm{~kg}$ bahan bakar menunjukkan total operating time yang paling tinggi yaitu 86 menit, tetapi berat abu yang dihasilkan juga lebih besar dibanding lainnya yaitu sebesar 38.3 gram. Pada pengujian tersebut proses pendidihan $3 \mathrm{~kg}$ air berlangsung cepat yaitu terjadi pada menit ke 12 . Hal ini dapat terjadi karena kompor terisi secara penuh oleh bahan bakar sehingga nyala api lebih dekat dengan panci/bejana yang digunakan. Proses pengujian kompor gasifikasi menggunakan bahan tongkol jagung dapat ditunjukkan pada Gambar 3 sebagai berikut.

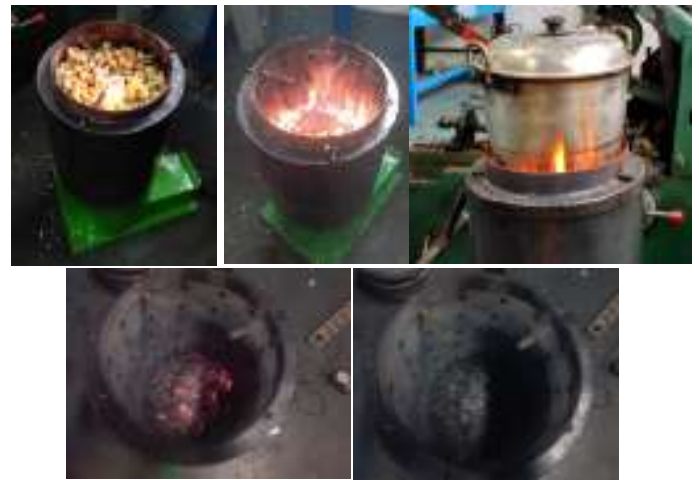

Gambar 3. Proses Pengujian Kompor Dengan Pendidihan Air $3 \mathrm{~kg}$.

Gambar 3 merupakan proses penggunaan kompor mulai dari start-up proses pendidihan air dan hingga bahan bakar menjadi abu.

\section{Evaluasi Performa kompor gasifikasi.}

Hasil analisis berdasarkan data pengujian kompor didapatkan beberapa nilai parameter yang terdapat pada Tabel 2 sebagai berikut.

Tabel 3. Parameter Output Hasil Perhitungan

\begin{tabular}{|c|c|c|c|c|c|}
\hline $\begin{array}{c}\text { No } \\
\text { Uji }\end{array}$ & $\begin{array}{c}\text { Weight } \\
\text { Fuel } \\
(\mathrm{kg})\end{array}$ & $\begin{array}{c}\text { FCR } \\
(\mathrm{kg} / \mathrm{h})\end{array}$ & $\begin{array}{c}\mathrm{SH} \\
(\mathrm{kCal})\end{array}$ & $\begin{array}{c}\mathrm{LH} \\
(\mathrm{kCal})\end{array}$ & $\begin{array}{c}\mathrm{QF} \\
(\mathrm{kCal})\end{array}$ \\
\hline 1 & 3 & 2.651 & 213 & 1620 & 7746.9 \\
\hline 2 & 2 & 1.928 & 142 & 1080 & 5164.6 \\
\hline 3 & 1 & 3.030 & 71 & 540 & 2582.3 \\
\hline
\end{tabular}

Data yang ditunjukkan pada Tabel 3 diketahui bahwa energi panas yang tersedia dalam bahan bakar semakin besar seiring bertambahnya jumlah bahan bakar yaitu 3 kg tongkol jagung. Hal ini dapat diamati dari panas laten dan panas sensibel yang dihasilkan. Namun dalam pengujian ini tidak terjadi keseragaman komsumsi bahan bakar. Hal ini dapat diketahui dari pengujian yang kedua bahwa laju komsumsi bahan bakar lebih sedikit dibanding percobaan lainnya yaitu $1.9 \mathrm{~kg} / \mathrm{h}$.

Perbedaan laju bahan bakar terjadi akan mempengaruhi power dari kompor yang dihasilkan seperti terdapat pada Tabel 4 sebagai berikut. Tabel 4. Daya dan Efesiensi Kompor Gasifikasi

\begin{tabular}{|c|c|c|c|}
\hline NO & Pi $(\mathrm{kWh})$ & Po $(\mathrm{kWh})$ & TE $(\%)$ \\
\hline 1 & 8.216 & 1.879 & 23.661 \\
\hline 2 & 5.975 & 1.367 & 23.661 \\
\hline 3 & 9.390 & 2.148 & 23.661 \\
\hline
\end{tabular}

Tabel 4 merupakan hasil analisis power input, output, dan efesiensi kompor gasifikasi biomassa. Berdasarkan hasil analisis dapat diamati bahwa keberagaman laju komsumsi bahan bakar mempengaruhi power input dari kompor tersebut. Adapun power input terendah yaitu $5.9 \mathrm{kwh}$ dan tertinggi sebesar $9.3 \mathrm{kWh}$. Sedangkan power output terendah adalah $1.8 \mathrm{kWh}$ dan tertinggi sebesar $2.1 \mathrm{~kW}$. Dari ketiga pengujian yang 
telah dilakukan didapatkan efesiensi kompor gasifikasi sebesar 23\%. Perbandingan jumlah bahan bakar dan power input ditunjukkan dalam Gambar 4 Sebagai berikut.

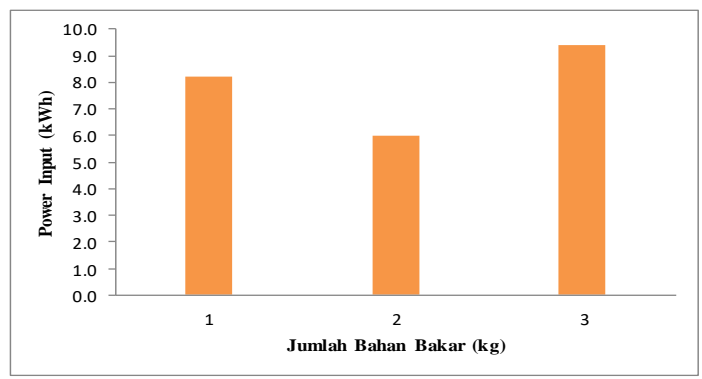

Gambar 4. Hubungan Jumlah bahan bakar Dan Power Input Kompor Gasifikasi.

Grafik yang ditunjukkan pada Gambar 4 dapat diamati bahwa power input terendah terdapat pada pengujian dengan $2 \mathrm{~kg}$ bahan kabar. Hal ini dapat terjadi karena laju komsumsi bahan bakar lebih lambat dibanding pengujian lainnya. Sedangkan hubungan power output dan jumlah bahan bakar terdapat Gambar 5 sebagai berikut.

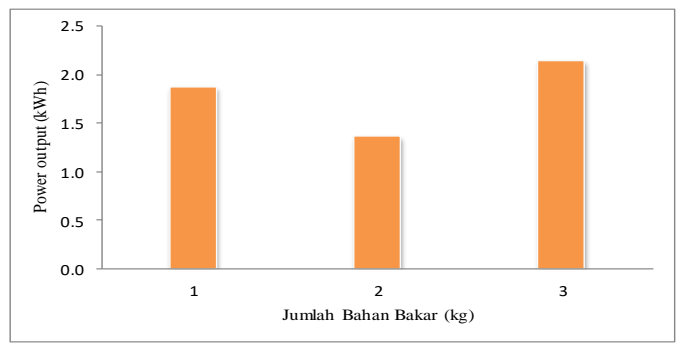

Gambar 4. Hubungan Jumlah Bahan Bakar Dan Power Output Kompor Gasifikasi.

Hasil analisis dapat ditunjukkan dalam diagram batang pada Gambar 5 didapat kesimpulan bahwa besaran nilai input berkorelasi dengan output yang dihasilkan. Dalam hal ini semakin besar power input maka semakin besar pula power output yang dimiliki oleh kompor tersebut. Hal ini dapat terjadi karena dipengaruhi oleh komsumsi bahan bakar yang dipasok kedalam kompor. Hubungan laju kebutuhan bahan bakar dengan jumlah bahan bakar dapat ditunjukkan pada Gambar 5 sebagai berikut.

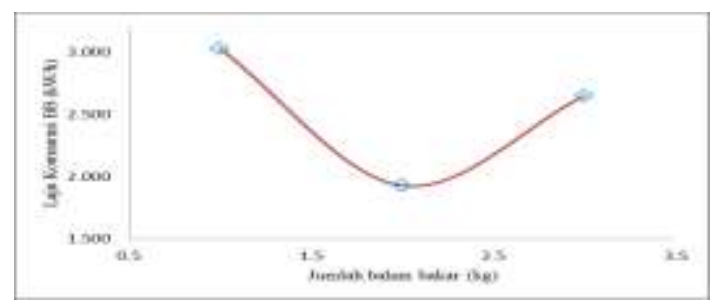

Gambar 5. Hubungan Laju Kebutuhan Bahan Bakar Dengan Jumlah Pasokan Bahan Bakar Kompor.

Grafik yang terdapat pada Gambar 5 diketahui bahwa pengujian $3 \mathrm{~kg}$ bahan bakar diperoleh laju komsumsi tongkol jagung sebesar $2,6 \mathrm{~kg} / \mathrm{h}$. Sedangkan pengujian untuk $1 \mathrm{~kg}$ bahan bakar didapat FCR sebesar 3,0 kg/h. Sementara pengjujian yang kedua menunjukkan kebutuhan bahan bakar yang paling rendah.

\subsection{Kesimpulan}

Dari hasil pengujian dan analisis data pengujian kompor gasifikasi dengan 3 variasi ukuran bahan bakar ,dapat diambil kesimpulan sebagai berikut :

1 Ukuran kompor biomassa berdiameter luar $30 \mathrm{~cm}$, ruang bakar memiliki $\varnothing 25 \mathrm{~cm}$, tinggi total $58 \mathrm{~cm}$ serta Gap antara dinding luar dan ruang bakar sebesar $2.5 \mathrm{~cm}$ memiliki kapasitas bahan bakar sebanyak $3 \mathrm{~kg}$ tongkol jagung.

2 Hasil analisis menunjukkan bahwa ukuran bahan bakar hanya dapat berpengaruh saat start-up yaitu tercepat pada menit ke empat dan terlama menit ke ke tujuh.

3 Komsumsi bahan bahkar berturut-turut didapat sebesar 2,6 kg/h; $1.9 \mathrm{~kg} / \mathrm{h}$ dan 3,0 kg/h

4 Total operating time dari kompor masing-masing sebesar 56; 78 dan 85 menit

5 Power input berdasarkan hasil analisis masingmasing sebesar 8,2; 5,9; dan 9,3 kg/h

6 Berdasarkan hasil analisis didapatkan power output terendah sebesar 1,$8 ; 1,3$ dan $1.89 \mathrm{kWh}$.

7 Efesiensi kompor gasifikasi pada penelitian adalah sebesar $23,6 \%$

\section{Daftar Pustaka}

1. Amiebenomo, S.O1;Igbesi F.C2 and Omorodion I.I Fabrication And Performance Evaluation Of An Improved Biomass Cook Stove, International Journal of Engineering Research \& Technology (IJERT) 2278-0181: Nigeria

2. Alexis T. Belonio and anderson rice husk gas stove handbook, (2005) Department of Agricultural Engineering and Environmental ManagemenCollege of Agriculture Central Philippine University.

3. Bambang Purwantana, Sunarto Ciptohadijoyo, Hasan Al-Banna, Yogi Rachmat, (2011). Kajian dimensi tenggorokan ruang reduksi gasifier tipe downdraft untuk gasifikasi limbah tongkol jagung.

4. James J. Jetter and Peter Kariher, (2008) Solidfuel household cook stoves: Characterization of 
performance and emissions. Biomass and Bioenergy 33- 294-305.Elsevier:USA

5. S.C. Bhattacharya *, D.O. Albina, Aung Myint Khaing (2002). Effects of selected parameters on performance and emission of biomass- red cook stoves gas quality. Biomass and Bioenergy 23- 387395.Elsevier: Thailand.

6. H. S. Mukunda*, S. Dasappa, P. J. Paul, N. K. S. Rajan, Mahesh Yagnaraman, D. Ravi Kumar and, (2010). Gasifier stoves - science, technology and field outreach. General artickel. India

7. Supramonoa dan Farah Inayati (2013). Performance of a Biomass-Gas Stove using Fuel of Rubber Wood Pellets.Proceeding of the 13 th international konfrence on QIR: yogyakarta indonesia.

8. P. Raman, J. Murali, D. Sakthivadivel, V.S. Vigneswaran, (2013). Performance evaluation of three types of forced draft cook stoves using fuel wood and coconut shell. The Energy and Resources Institute, Darbari Seth Block, IHC Complex, Lodhi Road, New Delhi 110 003, India 